OPEN ACCESS

Edited by:

George Tsiamis,

University of Patras, Greece

Reviewed by:

Yinghua Shi,

Henan Agricultural University, China

Fei Li,

Lanzhou University, China

*Correspondence:

Duanqin Wu

wuduanqin@caas.cn

Specialty section

This article was submitted to Systems Microbiology, a section of the journal

Frontiers in Microbiology

Received: 20 February 2021 Accepted: 16 September 2021 Published: 13 October 2021

Citation:

Kang J, Tang S, Zhong R, Tan Z and Wu D (2021) Alfalfa Silage

Treated With Sucrose Has an Improved Feed Quality and More Beneficial Bacterial Communities.

Front. Microbiol. 12:670165 doi: 10.3389/fmicb.2021.670165

\section{Alfalfa Silage Treated With Sucrose Has an Improved Feed Quality and More Beneficial Bacterial Communities}

\author{
Jinhe Kang ${ }^{1}$, Shaoxun Tang ${ }^{1}$, Rongzhen Zhong ${ }^{2}$, Zhiliang Tan ${ }^{1}$ and Duanqin Wu ${ }^{3 *}$ \\ ' CAS Key Laboratory for Agro-Ecological Processes in Subtropical Region, National Engineering Laboratory for Pollution \\ Control and Waste Utilization in Livestock and Poultry Production, Hunan Provincial Key Laboratory of Animal Nutrition \& \\ Physiology and Metabolism, South-Central Experimental Station of Animal Nutrition and Feed Science in Ministry \\ of Agriculture, Institute of Subtropical Agriculture, Chinese Academy of Sciences, Changsha, China, ${ }^{2}$ Northeast Institute of \\ Geography and Agroecology, Chinese Academy of Sciences, Changchun, China, ${ }^{3}$ Institute of Bast Fiber Crop, Chinese \\ Academy of Agricultural Sciences, Changsha, China
}

Alfalfa silage is one of the main roughages in the production of dairy cow, which can provide nutrition with high quality to improve milk quality and production. Sucrose additions have been widely used to improve the silage quality. In this study, the effects of sucrose on the fermentation quality and bacterial communities of alfalfa silage were investigated here using $0,0.5$, and $1 \%$ sucrose ensiling treatments for 15, 30, and 60 days. The ensiling time significantly decreased the crude fiber content and increased the ammonia nitrogen, acetic acid content, and the relative abundance of Enterococcus in the silages. The 1\% sucrose-treated silage at 60 days had the lowest neutral detergent fiber acid, acid detergent fiber, and crude fiber content and the highest relative feed value. Moreover, sucrose-treated silage contained less acetic acid, propionic acid, and butyric acid, and had a lower $\mathrm{pH}$ than the controls for each duration. Enterobacteriaceae, Klebsiella, and Enterococcus were the dominant genera in all groups, and the relative abundance of Enterococcus and Lactobacillus was higher in the 1\% sucrose-treated group than in the control. These results suggested that sucrose supplementation could improve alfalfa silage quality and increase its beneficial bacterial content.

Keywords: alfalfa, silage, additive, bacterial community, fermentation quality

\section{INTRODUCTION}

Alfalfa is a perennial legume plant with a high nutritional quality and good palatability, and has been widely planted in China (Sengul and Sengul, 2008; Xu et al., 2020). However, alfalfa harvests are seasonal, and it is difficult to preserve fresh alfalfa for a long time due to its high water content, especially during the rainy season in southern China. Consequently, alfalfa is normally ensiled for use as an animal fodder (Li et al., 2016). 
Alfalfa silage is one of the main roughages in the production of dairy cow, which can provide nutrition with high quality to improve milk quality and production. As a result, many practices have been applied to enhance the fermentation quality of alfalfa silage (Kung et al., 2003; Muck et al., 2018), including the supplementation of different sugar sources such as fructose, molasses, and pectin (Zhang et al., 2018; Wang et al., 2020). Sucrose additions have been widely used to improve the silage quality (Heinritz et al., 2012; Sun et al., 2020) because sucrose can increase the supply of substrates for the growth of lactic acid bacteria (Heinritz et al., 2012). Some lactobacilli can utilize citrate for the conversion of sugars into lactic acid and volatile fatty acids (de Figueroa et al., 2000). However, Lactobacillus plantarum addition is not favored in practical processing due to its difficulty in conservation and high price.

When ensiling forage, the types of microorganism that are present during fermentation also play a critical role (Kung et al., 2018). Thus, monitoring the ensiling process with respect to the changes in the chemical and microbial compositions could also help to improve our understanding of it (Namihira et al., 2010; Kung et al., 2018). Previous studies analyzed silage bacteria profiles to identify the ensiling processes using 16S rRNA sequencing (Ali et al., 2020). This experiment was carried out to further explore the effects of sucrose supplementation alone on ensiling characteristics and bacterial community compositions of alfalfa silage. The results of this study should provide theoretical support and guidance for future alfalfa silage production.

\section{MATERIALS AND METHODS}

\section{Forage Harvesting and Silage Preparation}

Alfalfa (Medicago sativa L.) was mechanically harvested at the early bloom stage in May 2019 from an experimental field located in Yuanjiang City, Hunan Province, China. A commercial sucrose (Guangzhou HUATANG Co., Ltd., Guangzhou, China) was used as additive and mixed with alfalfa before ensiling. The alfalfa stocks were individually cut into pieces that were approximately $2 \mathrm{~cm}$ in length and then mixed and randomly assigned to three groups: AL group (the control with no sucrose additions), AS1 group (with $0.5 \%$ sucrose additions), and AS2 group (with $1.0 \%$ sucrose additions). Thirty-six vacuum plastic bags $(25 \times 40 \mathrm{~cm}$; Zhengzhou Non-gshengle livestock equipment Co., Ltd., Zhengzhou, China) were used for the alfalfa ensiling $(10.0 \mathrm{~kg} / \mathrm{bag}$ ) and sealed by a vacuum sealer (Airmate Electric Co., Ltd., Shenzhen, China). The silage was maintained in the bags for durations of 15, 30, and 60 days, respectively. Three bags were randomly selected for each sucrose treatment at each time point. Silage samples were then transferred from the bags to plastic boxes via an opening for homogeneous mixing and then used for chemical and microbial analyses.

\section{Chemical Analyses}

The pre-ensiled alfalfa and silage samples were dried at $60^{\circ} \mathrm{C}$ for $48 \mathrm{~h}$ to a constant weight. Dry matter (DM) and crude protein $(\mathrm{CP})$ levels were analyzed according to AOAC standards
(AOAC International, 1995). Acid detergent fiber (ADF) and neutral detergent fiber (NDF) content was assessed using the methods described by Vansoest et al. (1991) by using a Fibretherm Fiber Analyzer (Gerhardt, Bonn, Germany). The gross energy (GE) was determined according to Bomb calorimeter method described by the International Organization for Standardization (ISO) 9,831-1,998 and by using isothermal auto-calorimeter (5E-AC8018, Changsha Kaide Measurement and Control Instrument Co., Ltd., China).

Silage sample $(20 \mathrm{~g})$ was homogenized with distilled water $(180 \mathrm{ml})$ and then filtered through four layers of cheesecloth and a qualitative filter paper. The $\mathrm{pH}$ of the water extract was measured using a $\mathrm{pH}$ meter (Model PHSJ4F, Shanghai Precision \& Scientific Instrument Co., Ltd., China). Ammonia nitrogen $\left(\mathrm{NH}_{3}-\mathrm{N}\right)$ was measured in the water extract as reported by Weatherburn (Weatherburn, 1967), using a spectrophotometer (8,500II, Thermo Electron Corporation, Waltham, MA, United States). The volatile fatty acid (VFA) content was analyzed as described previously by Kang et al. (2016).

\section{Assessment of the Feed Value}

The relative feed value (RFV) was calculated from digestible dry matter digestibility (DMD) and dry matter intake (DMI) using ADF (\%) and NDF (\%), respectively (Rohweder et al., 1978). The RFV of silages was calculated as follow: DMI $(\%)=120 / \mathrm{NDF}$, $\mathrm{DMD}(\%)=88.9-0.779 \times \mathrm{ADF}, \mathrm{RFV}=(\mathrm{DMI} \times \mathrm{DMD}) / 1.29$.

\section{Analysis of Bacterial Community}

The E.Z.N.A. ${ }^{\circledR}$ Stool DNA Kit (D4015, Omega, Inc., United States) was utilized to extract the DNA from each sample, according to the instructions of the protocol for pathogen detection. The region V3-V4 of the bacterial 16S rRNA gene was amplified with A200 Gradient Thermal Cycler (Hangzhou LongGene Scientific Instruments Co., Ltd). The primers were as follow: 341F (CCTACGGGNGGCWGCAG) and 806R (GGACTACHVGGGTWTCTAAT) (Wang et al., 2019a). The reaction mixtures of PCR amplification were included template DNA (25 ng), PCR Premix (12.5 $\mu \mathrm{l}$ ), and each primer $(2.5 \mu \mathrm{l})$ in $25 \mu \mathrm{l}$ total volume. The amplification conditions were as follows: an initial denaturation $\left(98^{\circ} \mathrm{C}, 30 \mathrm{~s}\right)$; 35 cycles of denaturation $\left(98^{\circ} \mathrm{C}, 10 \mathrm{~s}\right)$, annealing $\left(54^{\circ} \mathrm{C}, 30 \mathrm{~s}\right)$, extension $\left(72^{\circ} \mathrm{C}, 45 \mathrm{~s}\right)$; and extension $\left(72^{\circ} \mathrm{C}, 10 \mathrm{~min}\right)$. Amplicon pyrosequencing was conducted on an Illumina MiSeq platform (LC-Biotechnology Co., Ltd., Hangzhou, China). Paired-end reads was assigned to samples based on their unique barcode and truncated by cutting off the barcode and primer sequence when the average quality score on the 10-bp sliding window was below 20. Reads that contained undetected nucleotides (N) or were shorter than 200 bp were removed. Paired-end reads with $>10$ bp of overlap were merged using FLASH software (version 1.2.8). Quality-filtering on the raw tags was performed under specific filtering conditions to obtain the high-quality clean tags according to the fqtrim (version 0.94). Vsearch software (version 2.3.4) was used to filter the chimeric sequences. Sequences (similarity $>97 \%$ ) were assigned to the same operational taxonomic units (OTUs). The $\alpha$-diversity analysis 
was calculated using mothur (version 1.36.0). The most abundant sequences in each OTU were used for taxonomic classification by Ribosomal Database Project (RDP) Classifier (version 11.5) with the confidence threshold as $80 \%$. A principal coordinate analysis (PCoA) was completed via Muscle (version 3.8.31). The ANOSIM analysis was used to compare the differences between groups in PCoA analysis. Correlations between the main genera and silage quality were calculated via Spearman's correlation analysis (SPSS, version 19.0, Chicago, IL, United States). All the sequences in the current study were deposited to the sequence read archive (SRA) of the NCBI database under the accession number PRJNA704787.

\section{Statistical Analysis}

Two-way analysis of variance was utilized to evaluate the statistical significance. The fixed effects were the sucrose treatments, ensilage duration, and sucrose treatments by ensilage duration interactions, as calculated by the SPSS software (version 19.0, Chicago, IL, United States). All the data were presented as the means \pm SEM. Tukey's multiple comparison test was used to assess the differences between the means. Statistical significance was identified when $p<0.05$, and a tendency was set at $0.05<p<0.10$. GraphPad Prism software (Version 8.0, La Jolla, CA, United States) was used for all figures.

\section{RESULTS}

\section{Alfalfa Analysis Prior to Ensiling}

Fresh alfalfa had a CP of $170 \pm 2.5 \mathrm{~g} / \mathrm{kg}$ DM, CF of $263 \pm 8.0 \mathrm{~g} / \mathrm{kg}$ $\mathrm{DM}, \mathrm{NDF}$ of $460 \pm 11.0 \mathrm{~g} / \mathrm{kg} \mathrm{DM}, \mathrm{ADF}$ of $399 \pm 21.5 \mathrm{~g} / \mathrm{kg}$ $\mathrm{DM}$, and a gross energy (GE) of $16.92 \pm 0.1 \mathrm{MJ} / \mathrm{kg}$. The DMI, DDM, and RFV values of the fresh alfalfa were $2.61 \pm 0.06 \%$ body weight, $57.85 \pm 1.68 \% \mathrm{DM}$, and $116.96 \pm 0.60$, respectively. The observed species, Shannon, Simpson, and Chao 1 indices for the fresh alfalfa were $410.33 \pm 15.50,3.65 \pm 0.11,0.80 \pm 0.01$, and $758.71 \pm 74.54$, respectively (Table 1 ).

\section{Chemical Composition of the Alfalfa Silage}

The DM of the alfalfa silage was significantly affected $(p=0.009)$ by the sucrose additions. The DM content was significantly increased $(p<0.05)$ in the AS2 group when compared with that in the AL group at 30 days and was comparable among the three groups at 15 days and 60 days. The CP and ADF content of the alfalfa silage was significantly affected $(p<0.05)$ by the sucrose additions, ensiling duration, and their interactions. The CP content at 60 days was significantly higher than that at 30 days $(p<0.05)$. The control silage always had the highest NDF and ADF content. Furthermore, the NDF and ADF content was comparable among the three groups at 15 days and significantly decreased $(p<0.05)$ in the AS2 silage at 30 and 60 days. The lowest NDF and ADF content was recorded in the AS2 silage at 60 days, with values of 399 and $261 \mathrm{~g} / \mathrm{kg} \mathrm{DM}$, respectively. The CF content was significantly affected by the duration of ensiling $(p<0.05)$. After 60 days of ensiling, the minimum
CF content was $215 \mathrm{~g} / \mathrm{kg} \mathrm{DM}$ in the AS2 silage. In addition, the interaction between the sucrose treatments and the ensiling durations significantly affected the GE values of the silages $(p<0.05)$. The GE values ranged from 17.00 to $17.80 \mathrm{MJ} / \mathrm{kg}$ among the three groups with the highest values at 60 days (Table 2).

\section{Fermentation Dynamics of the Alfalfa Silage}

The fermentation characteristics of alfalfa silages with or without sucrose are presented in Table 3. The interactions between the sucrose treatments and the ensiling durations significantly affected the $\mathrm{pH}$ value $(p<0.01)$. Compared with the AL silage, the $1 \%$ sucrose addition treatment significantly decreased $(p<0.05)$ the $\mathrm{pH}$ value for each duration. However, the $\mathrm{pH}$ values were comparable between the AL and AS1 groups at 30 and 60 days and significantly decreased $(p<0.05)$ in the AS1 silage at 15 days when compared with that of the AL silage.

The $\mathrm{NH}_{3}-\mathrm{N}$ content was significantly affected $(p<0.05)$ by the sucrose additions and ensiling durations, and highest at terminal silage in AL, AS1, and AS2 silages. The $\mathrm{NH}_{3}-\mathrm{N}$ content was comparable among three groups at early phase of ensiling $(p>0.05)$. However, the $1.0 \%$ sucrose additions significantly decreased $(p<0.05)$ the $\mathrm{NH}_{3}-\mathrm{N}$ content compared with the AL silage at 30 and 60 days ensiling.

The contents of the acetic acid, propionic acid, and butyric acid in the alfalfa silage were significantly affected $(p<0.05)$ by the sucrose additions, ensiling durations, and their interactions. Compared with the AL silage, the $1 \%$ sucrose addition significantly decreased $(p<0.05)$ the acetic acid, propionic acid, and butyric acid content for each ensiling duration. In particular, the concentration of butyric acid was the lowest at 60 days.

TABLE 1 | Alfalfa analysis prior to ensiling.

\begin{tabular}{lcr}
\hline Item & Mean & SEM \\
\hline Chemical composition (g/kg DM) & & \\
CP & 170 & 2.5 \\
CF & 263 & 8.0 \\
NDF & 460 & 11.0 \\
ADF & 399 & 21.5 \\
GE (MJ/kg) & 16.92 & 0.1 \\
Assessment of feed value & & \\
DMl/\% BW & 2.61 & 0.06 \\
DDM/\% DM & 57.85 & 1.68 \\
RFV & 116.96 & 0.60 \\
Alpha diversity of the bacterial community & & \\
Observed species & 410.33 & 15.50 \\
Shannon & 3.65 & 0.11 \\
Simpson & 0.80 & 0.01 \\
Chao 1 & 758.71 & 74.54 \\
Coverage & 0.98 & 0.00 \\
\hline
\end{tabular}

CP, crude protein; $C F$, crude fiber; NDF, neutral detergent fiber; $A D F$, acid detergent fiber; GE, total energy; BW, body weight; DMI, dry matter intake; DDM, digestible dry matter; RFV, relative feed value; SEM, standard deviation of the mean. The data were calculated values based on estimating formulas. 
TABLE 2 | Chemical compositions of the alfalfa silages ( $g / k g ~ D M)$.

\begin{tabular}{|c|c|c|c|c|c|c|c|c|}
\hline \multirow[t]{2}{*}{ Items } & \multirow[t]{2}{*}{ Treatment } & \multicolumn{3}{|c|}{ Days ensiled } & \multirow[t]{2}{*}{ SEM } & \multicolumn{3}{|c|}{$p$-value } \\
\hline & & 15 & 30 & 60 & & $\mathbf{T}$ & D & I \\
\hline \multirow[t]{3}{*}{$\mathrm{DM}$} & $A L$ & 302 & $273^{\beta}$ & 290 & 9.02 & $\star \star$ & ns & ns \\
\hline & AS1 & 300 & $284^{\alpha \beta}$ & 287 & & & & \\
\hline & AS2 & 313 & $309^{\alpha}$ & 312 & & & & \\
\hline \multirow[t]{3}{*}{$\mathrm{CP}$} & $A L$ & $177^{b}$ & $166^{\mathrm{C}}$ & $188^{a}$ & 2.53 & $\star \star$ & 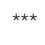 & * \\
\hline & AS1 & $180^{a}$ & $166^{b}$ & $182^{\mathrm{a}}$ & & & & \\
\hline & AS2 & $177^{b}$ & $172^{b}$ & $197^{a}$ & & & & \\
\hline \multirow[t]{3}{*}{ NDF } & $A L$ & 409 & $418^{\alpha}$ & $427^{\alpha}$ & 8.83 & * & ns & ns \\
\hline & AS1 & 422 & $413^{\alpha \beta}$ & $419^{\alpha \beta}$ & & & & \\
\hline & AS2 & 405 & $404^{\beta}$ & $399^{\beta}$ & & & & \\
\hline \multirow[t]{3}{*}{ ADF } & $\mathrm{AL}$ & $346^{a}$ & $324^{\alpha a b}$ & $304^{\alpha b}$ & 7.96 & $\star \star *$ & 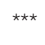 & * \\
\hline & AS1 & 338 & $318^{\alpha \beta}$ & $317^{\alpha \beta}$ & & & & \\
\hline & AS2 & $325^{a}$ & $316^{\beta a}$ & $261^{\beta b}$ & & & & \\
\hline \multirow[t]{3}{*}{ CF } & $A L$ & $270^{a b}$ & $279^{\alpha a}$ & $252^{\alpha b}$ & 3.57 & ns & $\star \star \star$ & ns \\
\hline & AS1 & 264 & $265^{\alpha \beta}$ & $261^{a b}$ & & & & \\
\hline & AS2 & $271^{a}$ & $257^{\beta a}$ & $215^{\beta b}$ & & & & \\
\hline \multirow[t]{3}{*}{ GE } & $A L$ & $17.10^{b}$ & $17.19^{b}$ & $17.61^{a}$ & 0.11 & ns & $\star \star \star$ & * \\
\hline & AS1 & $17.15^{\mathrm{b}}$ & $17.03^{b}$ & $17.80^{a}$ & & & & \\
\hline & AS2 & 17.00 & 16.85 & 17.68 & & & & \\
\hline
\end{tabular}

AL, $0 \%$ sucrose; AS1, $0.5 \%$ sucrose; AS2, $1.0 \%$ sucrose; DM, dry matter (g/kg fresh weight); CP, crude protein; NDF, neutral detergent fiber; ADF, acid detergent fiber; CF, crude fiber; GE, total energy (MJ/kg)T, treatments; $D$, ensiling time; I, interaction between ensiling duration and treatments; SEM, standard error of the mean.

$a, b, c$ Within a row, means with different superscripts are different $(p<0.05)$.

$\alpha, \beta, \gamma$ Within a column, means with different superscripts are different $(p<0.05)$.

${ }^{*} p<0.05 ;{ }^{* *} p<0.01 ;{ }^{* *} p<0.001$; and ns, not significant.

\section{Assessment of the Feed Value}

Sucrose additions significantly affected $(p<0.05)$ the DMI values, which were comparable among three groups at 15 days and significantly increased $(p<0.05)$ in the AS2 silage at 30 and 60 days. The DDM value of the alfalfa silage was significantly affected $(p<0.05)$ by the sucrose additions, ensiling durations, and their interactions. In addition, the DDM value was comparable among the three groups at 15 days and significantly increased $(p<0.05)$ in the AS2 silage at 30 and 60 days when compared with that in the AL silage. Furthermore, the DDM value reached its greatest value $(66.28 \% \mathrm{DM})$ in the AS2 silage at 60 days and did not change in the AL and AS1 groups with the increasing ensiling durations. The RFV value of the silage was significantly affected $(p<0.05)$ by the sucrose treatments and the interactions between the sucrose treatments and ensiling durations. The RFV values were comparable among the three groups at 15 days and increased $(p<0.05)$ in the AS2 silage at 30 and 60 days, when compared with the AL and AS1 silages, with the greatest value being 160.04 (Table 4).

\section{Bacterial Community Diversity in the Alfalfa Silage}

Bacterial diversity analysis of alfalfa silage ensiling day 15,30 , and 60 are presented in Table 5. The ensiling durations and the interactions between the sucrose treatments and ensiling
TABLE $3 \mid \mathrm{pH}, \mathrm{NH}_{3-} \mathrm{N}$, and VFA of the different alfalfa silages.

\begin{tabular}{|c|c|c|c|c|c|c|c|c|}
\hline \multirow[t]{2}{*}{ Items } & \multirow[t]{2}{*}{ Treatment } & \multicolumn{3}{|c|}{ Days ensiled } & \multirow[t]{2}{*}{ SEM } & \multicolumn{3}{|c|}{$p$-Value } \\
\hline & & 15 & 30 & 60 & & $\mathbf{T}$ & D & I \\
\hline \multirow[t]{3}{*}{$\mathrm{pH}$} & $A L$ & $5.52^{\alpha}$ & $5.45^{\alpha}$ & $5.37^{\alpha}$ & 0.078 & 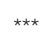 & ns & ** \\
\hline & AS1 & $5.15^{\beta a b}$ & $5.49^{\alpha a}$ & $4.96^{\alpha \beta b}$ & & & & \\
\hline & AS2 & $4.90^{\beta}$ & $4.75^{\beta}$ & $4.95^{\beta}$ & & & & \\
\hline \multirow{3}{*}{$\begin{array}{l}\mathrm{NH}_{3}-\mathrm{N} \\
(\mathrm{g} / \mathrm{kg} \mathrm{TN})\end{array}$} & $A L$ & $30.05^{\mathrm{b}}$ & $40.25^{\alpha a}$ & $42.23^{\alpha a}$ & 1.71 & * & 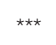 & ns \\
\hline & AS1 & $32.42^{\mathrm{b}}$ & $35.30^{\alpha \beta a b}$ & $41.45^{\alpha \beta a}$ & & & & \\
\hline & AS2 & $31.69^{b}$ & $33.01^{\beta a b}$ & $37.68^{\beta a}$ & & & & \\
\hline \multicolumn{9}{|c|}{ Concentration of VFA (g/kg DM) } \\
\hline \multirow{3}{*}{$\begin{array}{l}\text { Acetic } \\
\text { acid }\end{array}$} & $\mathrm{AL}$ & $22.91^{\alpha b}$ & $35.11^{\alpha b}$ & $49.44^{\alpha a}$ & 0.945 & 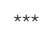 & 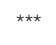 & 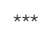 \\
\hline & AS1 & $17.09^{\beta b}$ & $22.24^{\beta a}$ & $23.23^{\beta a}$ & & & & \\
\hline & AS2 & $15.43^{\beta b}$ & $15.95^{\gamma \mathrm{b}}$ & $25.47^{\beta a}$ & & & & \\
\hline \multirow{3}{*}{$\begin{array}{l}\text { Propionic } \\
\text { acid }\end{array}$} & $\mathrm{AL}$ & $1.46^{\alpha c}$ & $8.20^{\alpha b}$ & $10.86^{\alpha a}$ & 0.103 & 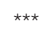 & $* \star \star$ & 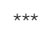 \\
\hline & AS1 & $1.21^{\alpha c}$ & $3.57^{\beta a}$ & $2.44^{\beta b}$ & & & & \\
\hline & AS2 & $0.50^{\beta c}$ & $1.03^{\gamma b}$ & $2.11^{\beta a}$ & & & & \\
\hline \multirow{3}{*}{$\begin{array}{l}\text { Butyric } \\
\text { acid }\end{array}$} & $A L$ & $6.95^{\alpha b}$ & $24.62^{\alpha a}$ & $22.07^{\alpha a}$ & 0.506 & 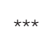 & 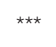 & 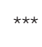 \\
\hline & AS1 & $5.23^{\alpha c}$ & $22.93^{\alpha a}$ & $16.72^{\beta b}$ & & & & \\
\hline & AS2 & $1.90^{\beta \mathrm{b}}$ & $13.05^{\beta a}$ & $13.78^{\mathrm{ra}}$ & & & & \\
\hline
\end{tabular}

$A L, 0 \%$ sucrose; $A S 1,0.5 \%$ sucrose; $A S 2,1.0 \%$ sucrose; DM, dry matter; $\mathrm{NH}_{3} \mathrm{~N}$, ammonia nitrogen; $\mathrm{TN}$, total nitrogen; T, treatments; $D$, ensiling duration; I, interaction between ensiling duration and treatments; SEM, standard error of means; VFA, volatile fatty acid.

$a, b, c$ Means within a row with different superscripts differ $(p<0.05)$.

$\alpha, \beta, \gamma$ Means within a column with different superscripts differ $(p<0.05)$.

${ }^{*} p<0.05 ;{ }^{* *} p<0.01 ;{ }^{* * *} p<0.001$; and ns, not significant.

TABLE 4 | Relative feed value of the alfalfa silage.

\begin{tabular}{|c|c|c|c|c|c|c|c|c|}
\hline \multirow[t]{2}{*}{ Items } & \multirow[t]{2}{*}{ Treatment } & \multicolumn{3}{|c|}{ Days ensiled } & \multirow[t]{2}{*}{ SEM } & \multicolumn{3}{|c|}{$p$-Value } \\
\hline & & 15 & 30 & 60 & & $\mathbf{T}$ & D & I \\
\hline \multirow[t]{3}{*}{ DMI/\% } & $\mathrm{AL}$ & $2.97^{\mathrm{a}}$ & $2.80^{\beta} \mathrm{ab}$ & $2.69^{\beta b}$ & 0.062 & * & ns & ns \\
\hline & AS1 & 2.85 & $2.91^{\alpha \beta}$ & $2.93^{\beta}$ & & & & \\
\hline & AS2 & 2.97 & $2.97^{\alpha}$ & $2.99^{\alpha}$ & & & & \\
\hline \multirow[t]{3}{*}{$\mathrm{DDM} / \%$} & $\mathrm{AL}$ & 60.81 & $63.05^{\beta}$ & $64.04^{\beta}$ & 0.620 & $\star \star \star *$ & 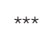 & * \\
\hline & AS1 & 62.54 & $64.13^{\alpha \beta}$ & $66.26^{\alpha \beta}$ & & & & \\
\hline & AS2 & $63.61^{b}$ & $64.30^{\alpha \mathrm{b}}$ & $66.28^{\alpha a}$ & & & & \\
\hline \multirow[t]{3}{*}{ RFV } & $A L$ & 140.06 & $137.10^{\gamma}$ & $133.86^{\beta}$ & 3.755 & ** & ns & * \\
\hline & AS1 & 138.21 & $144.57^{\beta}$ & $150.80^{\beta}$ & & & & \\
\hline & AS2 & 146.37 & $148.13^{\alpha}$ & $160.04^{\alpha}$ & & & & \\
\hline
\end{tabular}

AL, $0 \%$ sucrose; $A S 1,0.5 \%$ sucrose; $A S 2,1.0 \%$ sucrose; DMI, dry matter intake; $D D M$, digestible dry matter; RFV, relative feed value; T, treatments; $D$, ensiling duration; I, interaction between ensiling duration and treatments; SEM, standard error of the mean. The data were calculated based on the estimating formulas.

$a, b, c$ Means within a row with different superscripts differ $(p<0.05)$.

$\alpha, \beta, \gamma$ Means within a column with different superscripts differ $(p<0.05)$.

${ }^{*} p<0.05 ;{ }^{* *} p<0.01 ;{ }^{* * *} p<0.001 ; n s$, not significant.

durations significantly affected $(p<0.05)$ the OTUs, observed species, and Chao 1 indices of the alfalfa silage. The OTUs reached their highest value in the AS1 silage at 60 days. Furthermore, there was a U-shaped curvilinear relationship between the OTUs, Chao indices, and sucrose additions at 30 days, although they 
TABLE 5 | Alpha diversity of the alfalfa silage bacterial communities.

\begin{tabular}{|c|c|c|c|c|c|c|c|c|}
\hline \multirow[t]{2}{*}{ Items } & \multirow[t]{2}{*}{ Treatment } & \multicolumn{3}{|c|}{ Days ensiled } & \multirow[t]{2}{*}{ SEM } & \multicolumn{3}{|c|}{$p$-Value } \\
\hline & & 15 & 30 & 60 & & $\mathbf{T}$ & D & I \\
\hline \multirow[t]{3}{*}{ OTUS $_{S}$} & $\mathrm{AL}$ & 622 & $575^{\alpha \beta}$ & $675^{\gamma}$ & 48.13 & ns & $\star \star \star$ & ** \\
\hline & AS1 & $633^{b}$ & $449^{\beta \gamma b}$ & $956^{\alpha a}$ & & & & \\
\hline & AS2 & $540^{b}$ & $700^{\alpha a b}$ & $776^{\beta a}$ & & & & \\
\hline \multirow[t]{3}{*}{ Observed species } & $\mathrm{AL}$ & $493^{\alpha}$ & $487^{\alpha \beta}$ & 533 & 23.83 & ns & $\star \star$ & 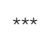 \\
\hline & AS1 & $491^{a b c}$ & $390^{\beta \gamma c}$ & $546^{a b}$ & & & & \\
\hline & AS2 & $380^{\beta b}$ & $543^{\alpha a}$ & $505^{a}$ & & & & \\
\hline \multirow[t]{3}{*}{ Chao 1} & $\mathrm{AL}$ & 863 & $784^{\alpha \beta}$ & 949 & 55.01 & ns & * & * \\
\hline & AS1 & $775^{\mathrm{bc}}$ & $672^{\beta \gamma c}$ & $920^{a b}$ & & & & \\
\hline & AS2 & 689 & $905^{\alpha}$ & 853 & & & & \\
\hline \multirow[t]{3}{*}{ Shannon } & $\mathrm{AL}$ & $4.35^{\mathrm{bc}}$ & $4.31^{c}$ & $5.11^{a b}$ & 0.192 & ns & $\star \star$ & ns \\
\hline & AS1 & 4.38 & 4.12 & 4.84 & & & & \\
\hline & AS2 & 4.08 & 4.79 & 4.59 & & & & \\
\hline \multirow[t]{3}{*}{ Simpson } & $\mathrm{AL}$ & $0.84^{b}$ & $0.81^{b}$ & $0.91^{a}$ & 0.026 & ns & $\star \star$ & ns \\
\hline & AS1 & 0.81 & 0.79 & 0.89 & & & & \\
\hline & AS2 & 0.80 & 0.88 & 0.87 & & & & \\
\hline \multirow[t]{3}{*}{ Coverage } & $\mathrm{AL}$ & 0.98 & 0.98 & 0.98 & - & - & - & - \\
\hline & AS1 & 0.98 & 0.98 & 0.98 & & & & \\
\hline & AS2 & 0.98 & 0.98 & 0.98 & & & & \\
\hline
\end{tabular}

AL, $0 \%$ sucrose; $A S 1,0.5 \%$ sucrose; $A S 2,1.0 \%$ sucrose; $T$, treatments; $D$, ensiling duration; I, interaction between ensiling duration and treatments; SEM, standard error of means. The data were calculated based on estimating formulas.

$a, b, c$ Means within a row with different superscripts differ $(p<0.05)$.

$\alpha, \beta, \gamma$ Means within a column with different superscripts differ $(p<0.05)$.

${ }^{*} p<0.05 ;{ }^{* *} p<0.01 ;{ }^{* *} p<0.001$; and $n s$, not significant.

were comparable in the OTU and Chao indices between the AL and AS2 groups. In addition, the Shannon and Simpson indices were influenced $(p<0.01)$ by the ensiling duration. Moreover, the Simpson index reached its highest value in the AL group after 60 days of ensiling. However, the Shannon and Simpson indices were comparable among the three groups for each ensiling duration.

Principal coordinates analysis (PCoA) which was UniFracbased showed a distinct clustering of the microbiota compositions for each group $(R=0.4973, p=0.001)$ (Figure 1A). Principle coordinates 1 and 2 accounted for $22.97 \%$ and $10.81 \%$ of the total variance, respectively (Figure 1A). Taxonomic analysis showed that the microbiota of the alfalfa silage was represented by two major phyla: Proteobacteria and Firmicutes (Figure 1B). The relative abundance of these two major phyla was significantly affected $(p<0.001)$ by the sucrose addition, ensiling duration, and their interactions. Moreover, the relative abundance of Proteobacteria reached its lowest value and that of Firmicutes reached its highest value in the AS2 group after 60 days of ensiling (Table 6).

At the genus level, Enterobacteriaceae, Klebsiella, and Enterococcus were dominant in the alfalfa silages, followed by Enterobacter, Pantoea, Lactobacillus, Proteus, Acinetobacter, and Bifidobacterium (Figure 1C). The relative abundances of Enterobacteriaceae, Enterococcus, Pantoea, and Proteus were significantly affected $(p<0.05)$ by the sucrose addition, ensiling duration, and their interactions. The relative abundance of Klebsiella was significantly affected $(p<0.01)$ by the sucrose addition, the interaction of sucrose addition, and ensiling duration. The relative abundances of Enterobacter, Lactobacillus, and Bifidobacterium were significantly affected $(p<0.01)$ by the ensiling duration. Furthermore, the relative abundances of Enterobacteriaceae, and Klebsiella were significantly decreased $(p<0.05)$ and that of Enterococcus and Lactobacillus were significantly increased $(p<0.05)$ in the AS2 group at 60 days when compared with that in the AL group or the AS1 group. In addition, the relative abundance of Pantoea in the AS2 group was lower than that in the AS1 group at 60 days (Table 7 ).

\section{Relationship Between Main Genera and Silage Quality}

Spearman correlation analysis illustrated that Enterobacter, Enterobacteriaceae, and Pantoea were positively correlated with ammonia-N ( $r=0.49,0.51$, and 0.58 , respectively, $p<0.05)$, ADF $(r=0.39,0.63$, and 0.55 , respectively, $p<0.05)$, and CF $(r=0.40,0.54$, and 0.70 , respectively, $p<0.05)$ contents, while they were negatively correlated with the CP content ( $r=-0.71,-0.57$, and -0.66 , respectively, $p<0.05$ ). Also, Bifidobacterium, Clostridium, Serratia, Lactobacillus, and Pediococcus were negatively correlated with CP $(r=-0.47$, $-0.43,-0.46,-0.58$, and -0.57 , respectively, $p<0.05)$ content. Meanwhile, Bifidobacterium, Clostridium, Lactobacillus, and Pediococcus were positively correlated with the concentration of ammonia-N ( $r=0.48,0.50,0.47$, and 0.50 , respectively, $p<0.05)$ and CF ( $r=0.37,0.23,0.31$, and 0.38 , respectively, $p<0.05)$ contents, and Bifidobacterium was positively correlated with the $\operatorname{ADF}$ content $(r=0.52, p<0.05)$ (Figure 2).

Coprococcus, Enterococcus, Amphibacillus, Tissierella, Jeotgalibaca, and Proteus displayed positive correlation with CP content $(r=0.45,0.67,0.62,0.62,0.69$, and 0.69 , respectively, $p<0.05)$ and GE value $(r=0.54,0.40,0.60$, $0.65,0.66$, and 0.51 , respectively, $p<0.05)$. However, they showed negative correlation with ammonia-N $(r=-0.39$, $-0.58,-0.59,-0.64$, and -0.64 , respectively, $p<0.05)$, $\operatorname{ADF}(r=-0.59,-0.42,-0.50,-0.62,-0.49$, and -0.58 , respectively, $p<0.05)$, and CF $(r=-0.59,-0.61,-0.60$, $-0.70,-0.58$, and -0.40 , respectively, $p<0.05)$ contents. Likewise, Lysinibacillus, Bacillus, and Providencia were positively correlated with the CP content $(r=0.52,0.51$, and 0.49 , respectively, $p<0.05)$ and negatively correlated with ammonia$\mathrm{N}$ content $(r=-0.52,-0.50$, and -0.46 , respectively, $p<0.05)$. The ADF content was also negatively correlated with Providencia and Acinetobacter ( $r=-0.43,-0.42$, respectively, $p<0.05$ ). The GE value was positively correlated with Lysinibacillus $(r=0.40$, $p<0.05)$. In addition, the acetate concentration was negatively correlated with Pediococcus and Lactobacillus $(r=-0.39,-0.41$, respectively, $p<0.05$ ), and positively correlated with Proteus, Jeotgalibaca, and Tissierella ( $r=0.47,0.50$, and 0.41 , respectively, $p<0.05$ ) (Figure 2).

\section{DISCUSSION}

Silage $\mathrm{pH}$ is the key factor influencing the fermentation quality (Muck et al., 2018). In the AS2 groups, the $\mathrm{pH}$ value rapidly 


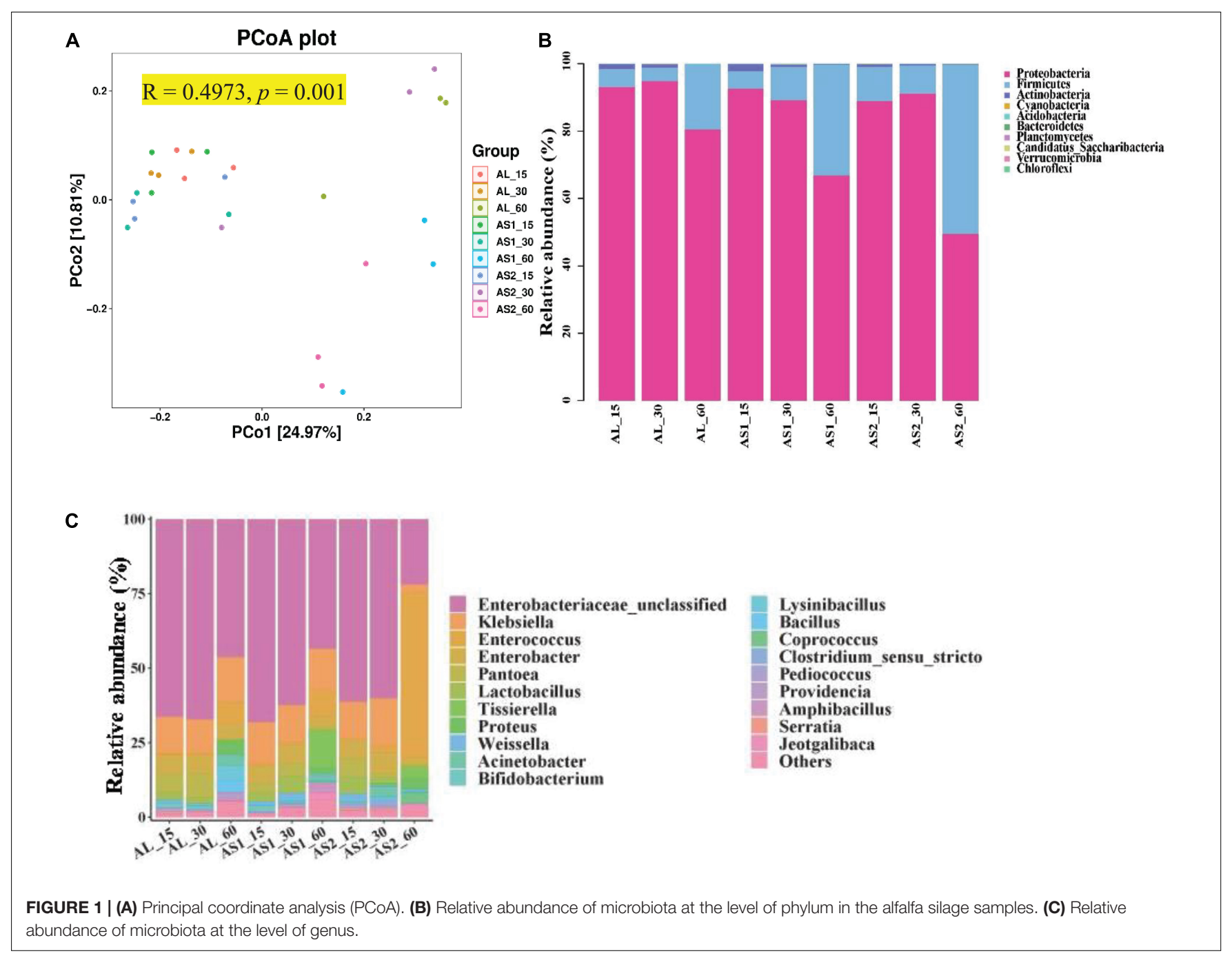

declined to a significantly lower level than the $\mathrm{pH}$ value in $\mathrm{AL}$ group at the early stage of fermentation and was stable with the prolonged ensiling time. Moreover, the production of butyric

TABLE 6 | Relative abundance of the major phyla (\%) of the alfalfa silage.

\begin{tabular}{|c|c|c|c|c|c|c|c|c|}
\hline \multirow[t]{2}{*}{ Items } & \multirow[t]{2}{*}{ Treatment } & \multicolumn{3}{|c|}{ Days ensiled } & \multirow[t]{2}{*}{ SEM } & \multicolumn{3}{|c|}{$p$-Value } \\
\hline & & 15 & 30 & 60 & & $\mathbf{T}$ & D & I \\
\hline \multirow[t]{3}{*}{ Proteobacteria } & $\mathrm{AL}$ & 93.06 & 94.87 & $80.51^{\alpha}$ & 2.28 & 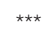 & 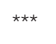 & $* \star \star$ \\
\hline & AS1 & 92.57 & 89.14 & $80.87^{\alpha}$ & & & & \\
\hline & AS2 & $88.88^{a}$ & $91.11^{a}$ & $32.89^{\beta b}$ & & & & \\
\hline \multirow[t]{3}{*}{ Firmicutes } & $A L$ & $5.31^{\mathrm{ab}}$ & $4.00^{\mathrm{b}}$ & $19.41^{\beta a}$ & 1.95 & 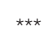 & 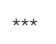 & *** \\
\hline & AS1 & 5.23 & 9.94 & $18.88^{\beta}$ & & & & \\
\hline & AS2 & $10.21^{b}$ & $8.35^{\mathrm{b}}$ & $66.78^{\alpha a}$ & & & & \\
\hline
\end{tabular}

AL, 0\% sucrose; AS1, 0.5\% sucrose; AS2, $1.0 \%$ sucrose; T, treatments; $D$, ensiling duration; I, interaction between ensiling duration and treatments; SEM, standard error of means. The data were calculated based on estimating formulas.

$a, b, c$ Means within a row with different superscripts differ $(p<0.05)$.

$\alpha, \beta, \gamma$ Means within a column with different superscripts differ $(p<0.05)$.

${ }^{* * *} p<0.001$. acid results in the loss of energy and butyric acid usually results in livestock reducing their intake. So, it is unwanted in silage (Muck, 2010). The significantly lower $\mathrm{pH}$ value and butyric acid content in the AS2 silage than in the AL silage in this study indicated that the growth of harmful bacteria was inhibited by the $\mathrm{pH}$ and that sucrose inclusion could improve the quality of the ensiling fermentation products. This was consistent with the results of a previous study that $0.67 \%$ sucrose addition decreased the $\mathrm{pH}$ value of alfalfa silage after 120 days of fermentation (Li et al., 2016).Relative feed value (RFV) is an evaluation criteria to express the forage quality. The more of the RFV, the better is the forage quality (Rohweder et al., 1978). The higher RFV values in the AS2 silage at 30 and 60 days fermentation indicated that $1 \%$ sucrose addition improved the feeding quality of alfalfa silage.

The ammonia-N content usually reflects the silage proteolysis during ensiling, and is commonly driven by plant enzyme protease and proteolytic Clostridia (Wang et al., 2019c). The lower ammonia-N content in AS2 at terminal silage indicated that the sucrose additions contributed to the protein preservation. This result was consistent with previous study that sucrose 
TABLE 7 | Relative abundance of genera (\%) of the alfalfa silage.

\begin{tabular}{|c|c|c|c|c|c|c|c|c|}
\hline \multirow[t]{2}{*}{ Items } & \multirow[t]{2}{*}{ Treatment } & \multicolumn{3}{|c|}{ Days ensiled } & \multirow[t]{2}{*}{ SEM } & \multicolumn{3}{|c|}{$p$-Value } \\
\hline & & 15 & 30 & 60 & & $\mathbf{T}$ & D & I \\
\hline \multirow[t]{3}{*}{ Enterobacteriaceae } & $A L$ & $66.24^{a}$ & $67.08^{a}$ & $46.22^{a b}$ & 3.22 & $\star \star \star *$ & $\star \star \star$ & ** \\
\hline & AS1 & $68.15^{\mathrm{a}}$ & $62.43^{a b}$ & $55.24^{\alpha b}$ & & & & \\
\hline & AS2 & $61.18^{a}$ & $60.06^{a}$ & $21.83^{\beta b}$ & & & & \\
\hline \multirow[t]{3}{*}{ Klebsiella } & $\mathrm{AL}$ & 12.37 & 11.41 & $15.00^{\alpha \beta}$ & 1.25 & ** & ns & 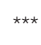 \\
\hline & AS1 & $13.92^{b}$ & $12.38^{b}$ & $19.95^{\alpha a}$ & & & & \\
\hline & AS2 & $12.52^{a}$ & $15.65^{\mathrm{a}}$ & $2.88^{\beta b}$ & & & & \\
\hline \multirow[t]{3}{*}{ Enterococcus } & $\mathrm{AL}$ & $0.46^{a b}$ & $0.36^{b}$ & $7.38^{\beta a}$ & 0.06 & $\star \star \star ~$ & $\star \star \star$ & 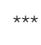 \\
\hline & AS1 & $0.49^{b}$ & $0.52^{b}$ & $6.01^{\beta a}$ & & & & \\
\hline & AS2 & $0.51^{b}$ & $2.63^{b}$ & $55.19^{\alpha a}$ & & & & \\
\hline \multirow[t]{3}{*}{ Enterobacter } & $\mathrm{AL}$ & $6.43^{\mathrm{a}}$ & $6.49^{a}$ & $4.93^{b}$ & 0.12 & ns & $\star \star \star ~$ & ns \\
\hline & AS1 & $6.04^{a}$ & $6.47^{\mathrm{a}}$ & $4.36^{b}$ & & & & \\
\hline & AS2 & $6.00^{\mathrm{a}}$ & $6.88^{a}$ & $2.56^{b}$ & & & & \\
\hline \multirow[t]{3}{*}{ Pantoea } & $\mathrm{AL}$ & $6.13^{a}$ & $8.03^{\alpha a}$ & $0.56^{\alpha \beta b}$ & 0.08 & * & $\star \star \star$ & $\star \star$ \\
\hline & AS1 & $3.24^{a b}$ & $4.48^{\alpha \beta a}$ & $0.89^{\alpha b}$ & & & & \\
\hline & AS2 & $6.27^{\mathrm{a}}$ & $1.53^{\beta a b}$ & $0.28^{\beta b}$ & & & & \\
\hline \multirow[t]{3}{*}{ Lactobacillus } & $\mathrm{AL}$ & 5.28 & 2.05 & $0.03^{\beta}$ & 0.001 & ns & $\star *$ & ns \\
\hline & AS1 & $2.89^{a b}$ & $5.60^{a}$ & $0.04^{\beta b}$ & & & & \\
\hline & AS2 & 5.67 & 1.87 & $0.39^{\alpha}$ & & & & \\
\hline \multirow[t]{3}{*}{ Proteus } & $\mathrm{AL}$ & $0.00^{b}$ & $0.00^{b}$ & $4.71^{\alpha \mathrm{a}}$ & 0.01 & $\star \star \star$ & $\star \star \star$ & 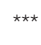 \\
\hline & AS1 & $0.00^{b}$ & $0.00^{b}$ & $1.08^{\beta a}$ & & & & \\
\hline & AS2 & $0.00^{b}$ & $0.81^{b}$ & $3.46^{\alpha a}$ & & & & \\
\hline \multirow[t]{3}{*}{ Acinetobacter } & $\mathrm{AL}$ & $0.06^{b}$ & $0.08^{\beta b}$ & $3.77^{\mathrm{a}}$ & 0.02 & ns & ns & ns \\
\hline & AS1 & $0.04^{b}$ & $0.31^{\alpha \beta b}$ & $1.89^{\mathrm{a}}$ & & & & \\
\hline & AS2 & 0.12 & $3.03^{\alpha}$ & 0.07 & & & & \\
\hline \multirow[t]{3}{*}{ Bifidobacterium } & $A L$ & 1.05 & 0.98 & $0.00^{\beta}$ & 0.01 & ns & $\star \star$ & ns \\
\hline & AS1 & $2.04^{a}$ & $0.51^{a b}$ & $0.03^{\alpha \beta b}$ & & & & \\
\hline & AS2 & 0.69 & 0.36 & $0.11^{\alpha}$ & & & & \\
\hline
\end{tabular}

AL, $0 \%$ sucrose; $A S 1,0.5 \%$ sucrose; $A S 2,1.0 \%$ sucrose; $T$, treatments; $D$, ensiling duration; I, interaction between ensiling duration and treatments; SEM, standard error of means. The data were calculated based on estimating formulas.

$a, b, c$ Means within a row with different superscripts differ $(p<0.05)$.

$\alpha, \beta, \gamma$ Means within a column with different superscripts differ $(p<0.05)$.

${ }^{*} p<0.05 ;{ }^{* *} p<0.01 ;{ }^{* *} p<0.001$; and $n s$, not significant.

additions decreased ammonia- $\mathrm{N}$ content in alfalfa silage (Li et al., 2020). Moreover, the loss of DM is exacerbated by the acetic acid bacteria. Therefore, the acetic acid content is closely related to the loss of DM in silage (Guo et al., 2020). In this study, the lower acetic acid content after 60 days of ensiling in both the AS1 and AS2 silages suggested that sucrose additions might decrease the loss of DM in the silage. A similar observation has been reported previously, as $0.67 \%$ sucrose additions were found to decrease the acetic acid content of alfalfa silage after 120 days of fermentation (Li et al., 2016). Moreover, Enterobacteriaceae can enhance the production of ammonia-N (Queiroz et al., 2018), and acetic acid is mainly produced by the Enterobacteriaceae during the fermentation process (Wang et al., 2020). Therefore, the lower ammonia-N and acetic acid contents observed in the AS2 group coincided with the significantly lower Enterobacteriaceae populations in the AS2 group than AL group after 60 days of fermentation.

The coverage of microbial DNA samples in the present study was nearly 1, suggesting that most bacteria in the samples were represented by $16 \mathrm{~S}$ rRNA sequences. Generally, the alpha diversity of the bacteria was estimated by using the number of OTUs, Chao1, and Shannon index. The ensiling time significantly affected $\alpha$ diversity at present study, indicating that the richness and evenness of bacterial community was influenced by the silage time. The similar Shannon and Chaol indices among the three groups on days 15 and 60 silage in current study indicated that the richness and evenness of the bacterial communities was stable at initial and terminal silage when the sucrose was supplemented. The PCoA analysis in this study suggested that sucrose addition had an effect on microbial composition. This result was similar with the report that alfalfa had different bacterial population after ensiling, but the bacterial diversity was changed very little (McGarvey et al., 2013). The reason for this phenomenon might be that the changes in the level of some taxonomic groups are offset by opposite changes in other groups (Hartmann and Windmer, 2006). In addition, the silage time significantly affected $\alpha$ diversity at present study, indicating that the richness and evenness of bacterial community was influenced by the silage time.

After ensiling, Proteobacteria and Firmicutes became the dominant phyla, with or without sucrose additions. A previous investigation similarly showed that the most abundant phyla in mulberry silage were Proteobacteria and Firmicutes, with or without sucrose additions, after 60 days of ensiling (Wang et al., 2019b). The domination of these two phyla might be due to the low $\mathrm{pH}$ and anaerobic conditions of the silage, which were conducive to their growth. Firmicutes are vital acid hydrolytic microbes under anaerobic condition, which could produce numerous extracellular enzymes (Wang et al., 2020). The significantly lower Proteobacteria and higher Firmicutes populations in AS2 group than AL group after 60 days of fermentation indicated that the bacterial population structure of the alfalfa shifted significantly during the ensiling process when the $1 \%$ sucrose was added. The reason for this result was that the acidic and anaerobic environment during ensiling is beneficial for the proliferation of Firmicutes (Keshri et al., 2018). This result was in accordance with previous report that the amount of Proteobacteria was declined, while the numbers of Firmicutes was markedly increased in alfalfa silage (McGarvey et al., 2013).

The genera Enterococcus and Lactobacillus are known to dominate the fermentation of forage products when anaerobic conditions are formed. Furthermore, the silage quality was improved by using these genera (Zhang et al., 2017). Moreover, Lactobacillus and Enterococcus belong to the lactic acid bacteria, and they initiate lactic fermentation at the early ensiling process, while Enterococcus had lower tolerance to low $\mathrm{pH}$ than Lactobacillus (Bai et al., 2021). However, Enterobacteriaceae, Klebsiella, and Enterococcus were the dominant genera in the current study, which were different from the previous observed microflora in alfalfa silages (McGarvey et al., 2013; Guo et al., 2018). Moreover, we observed a higher relative abundance of Enterococcus in the AS2 silage in the present study. Enterococcus is often applied to enhance the fermentation characteristics and play a pivotal role in accelerating the lactic 


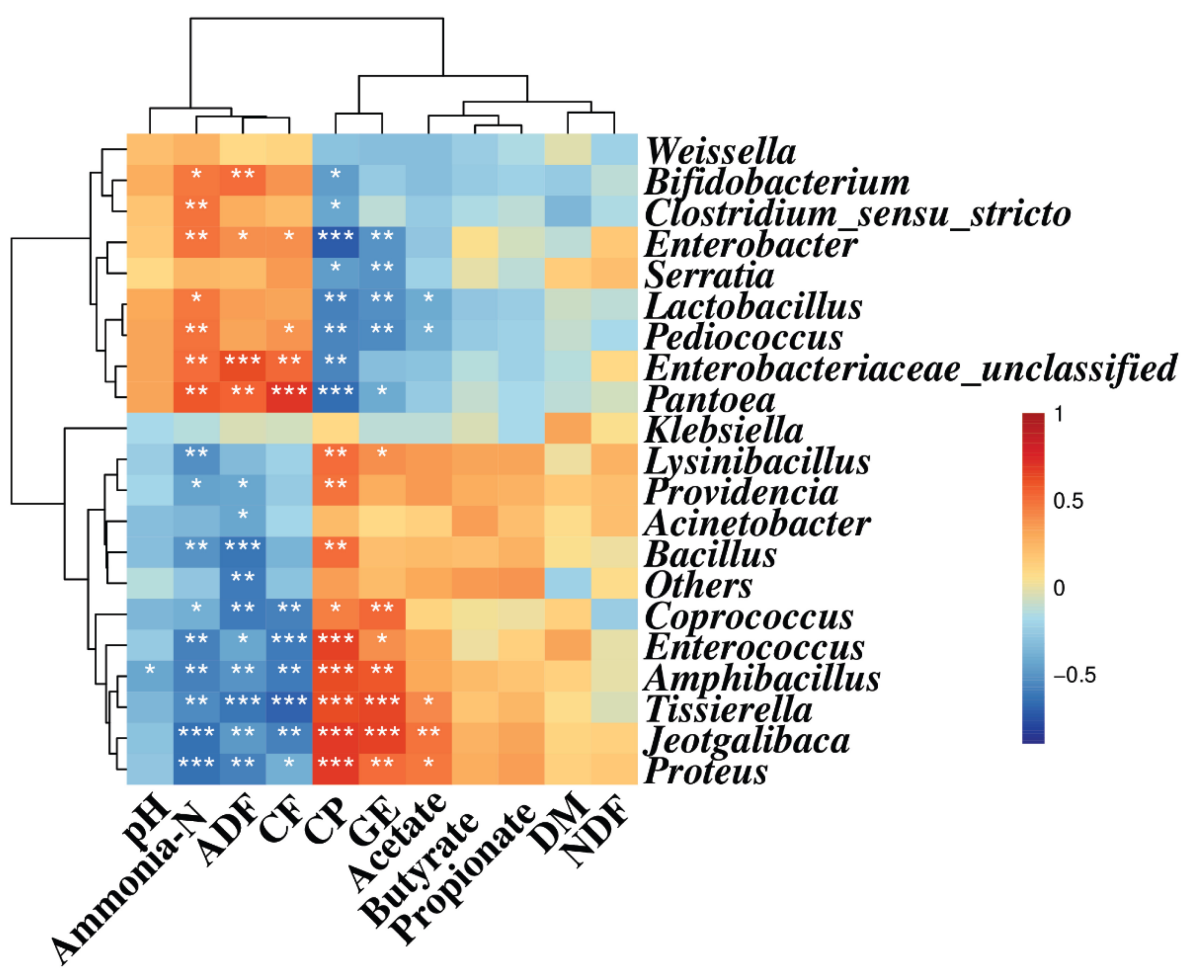

FIGURE 2 | Spearman correlation heatmap between the main genera and silage quality. R was presented in different colors; the right side of the legend is the color range of different $\mathrm{R}$ values. AL, control; AS1, $0.5 \%$ sucrose; AS2, $1.0 \%$ sucrose. The value of $p \leq 0.05$ is marked with "*”, $p \leq 0.01$ is marked with "**”, and

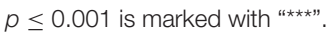

acid fermentation and building an anaerobic acidic circumstance for the development of Lactobacillus (Cai et al., 1998). The probable reason for this result was the slow rate of $\mathrm{pH}$ decline in AS2 silages.

Lactobacillus plays an important role in $\mathrm{pH}$ reduction during the later stages of lactic fermentation (da Silva et al., 2020). Although Lactobacillus was not the dominant genera in the AS2 silage in this study, the relative abundance of Lactobacillus in the AS2 silage was greater than in the AL silage in the current study. This indicated that sucrose addition can promote the fermentation quality of alfalfa silage. Similarly, the alfalfa silages were relatively abundant in lactic acid bacteria when treated with E. coli O157:H7 and Lactobacillus plantarum (Ogunade et al., 2018).

The results shown in Figure 2 indicated that there was an interaction between the bacterial community and silage fermentation. The negative correlation among Coprococcus, Enterococcus, Amphibacillus, Tissierella, Jeotgalibaca, Proteus, and ammonia-N concentration in the present study indicated their contribution to protein preservation.

\section{CONCLUSION}

The ensiling time significantly decreased the crude fiber content, and increased the ammonia nitrogen, acetic acid content, and the relative abundance of Enterococcus in the silages. Supplementing alfalfa silage samples with different doses of sucrose decreased their $\mathrm{pH}$ levels and NDF, propionic acid, and butyric acid content. There was an increment in the RFV levels with the increments of the sucrose supplementations. Furthermore, the reduced levels of butyric acid suppressed harmful bacteria and the relative abundance of Lactobacillus and Enterococcus in the silage increased. In conclusion, our results suggest that sucrose supplementation improves the feeding quality of alfalfa silage.

\section{DATA AVAILABILITY STATEMENT}

The datasets presented in this study can be found in online repositories. The names of the repository/repositories and accession number(s) can be found below: https://www.ncbi.nlm. nih.gov/sra/PRJNA704787, PRJNA704787.

\section{AUTHOR CONTRIBUTIONS}

JK handled the validation, investigation, methodology, visualization, writing of the original draft, and reviewing and editing of the manuscript. ST contributed to the validation, formal analysis, reviewing, editing, and writing of the draft. RZ contributed to the validation, reviewing, editing, 
and writing of the draft. ZT contributed to the validation, writing, reviewing, editing of the manuscript, and supervision. DW participated in the validation, conceptualization, supervision, writing, reviewing, editing of the manuscript, and was in charge of the funding acquisition and project administration. All authors contributed to the article and approved the submitted version.

\section{REFERENCES}

Ali, N., Wang, S. R., Zhao, J., Dong, Z. H., Li, J. F., Nazar, M., et al. (2020). Microbial diversity and fermentation profile of red clover silage inoculated with reconstituted indigenous and exogenous epiphytic microbiota. Bioresource Technol. 314:123606. doi: 10.1016/j.biortech.2020.123606

AOAC International (1995). Official methods of analysis of AOAC International. Arlington: AOAC International.

Bai, J., Ding, Z. T., Ke, W. C., Xu, D. M., Wang, M. S., Huang, W. K., et al. (2021). Different lactic acid bacteria and their combinations regulated the fermentation process of ensiled alfalfa: ensiling characteristics, dynamics of bacterial community and their functional shifts. Microb. biotechnol. 14, 11711182. doi: 10.1111/1751-7915.13785

Cai, Y., Benno, Y., Ogawa, M., Ohmomo, S., Kumai, S., and Nakase, T. (1998). Influence of Lactobacillus spp. from an inoculant and of Weissella and Leuconostoc spp. from forage crops on silage fermentation. Appl. Environ. Microbiol. 64, 2982-2987.

da Silva, E. B., Smith, M. L., Savage, R. M., Polukis, S. A., Drouin, P., and Kung, L. (2020). Effects of Lactobacillus hilgardii 4785 and Lactobacillus buchneri 40788 on the bacterial community, fermentation and aerobic stability of high-moisture corn silage. J. Appl. Microbiol. 2020:14892. doi: $10.1111 /$ jam. 14892

de Figueroa, R. M., Alvarez, F., Holgado, A. P. D., Oliver, G., and Sesma, F. (2000). Citrate utilization by homo- and heterofermentative lactobacilli. Microbiol. Res. 154, 313-320. doi: 10.1016/S0944-5013(00)80005-1

Guo, X. S., Bai, J., Li, F. H., Xu, D. M., Zhang, Y. X., Bu, D. P., et al. (2020). Effects of malate, citrate, succinate and fumarate on fermentation, chemical composition, aerobic stability and digestibility of alfalfa silage. Anim. Feed Sci. Tech. 268:114604. doi: 10.1016/j.anifeedsci.2020.114604

Guo, X. S., Ke, W. C., Ding, W. R., Ding, L. M., Xu, D. M., Wang, W. W., et al. (2018). Profiling of metabolome and bacterial community dynamics in ensiled Medicago sativa inoculated without or with Lactobacillus plantarum or Lactobacillus buchneri. Sci. Rep-Uk. 8:357. doi: 10.1038/s41598-017-18348-0

Hartmann, M., and Windmer, F. (2006). Community structure analysis are more sensitive to differences in soil bacterial communities than anonymous diversity indices. Appl. Environ. Microbiol. 72, 7804-7812. doi: 10.1128/AEM.01464-06

Heinritz, S. N., Martens, S. D., Avila, P., and Hoedtke, S. (2012). The effect of inoculant and sucrose addition on the silage quality of tropical forage legumes with varying ensilability. Anim. Feed Sci. Tech. 174, 201-210. doi: 10.1016/j. anifeedsci.2012.03.017

Kang, J. H., Zeng, B., Tang, S. X., Wang, M., Han, X. F., Zhou, C. S., et al. (2016). Effects of Momordica charantia saponins on in vitro ruminal fermentation and microbial population. Asian Austral. J. Anim. 29, 500-508. doi: 10.5713/ajas.15. 0402

Keshri, J., Chen, Y., Pinto, R., Kroupitski, Y., Weinberg, Z. G., and Sela Saldinger, S. (2018). Microbiome dynamics during ensiling of corn with and without Lactobacillus plantarum inoculant. Appl. Microbiol. Biotechnol. 102, 4025-4037. doi: 10.1007/s00253-018-8903-y

Kung, L., Taylor, C. C., Lynch, M. P., and Neylon, J. M. (2003). The effect of treating alfalfa with Lactobacillus buchneri 40788 on silage fermentation, aerobic stability, and nutritive value for lactating dairy cows. J. Dairy Sci. 86, 336-343. doi: 10.3168/jds.S0022-0302(03)73611-X

Kung, L. M., Shaver, R. D., Grant, R. J., and Schmidt, R. J. (2018). Silage review: Interpretation of chemical, microbial, and organoleptic components of silages. J. Dairy Sci. 101, 4020-4033. doi: 10.3168/jds.2017-13909

Li, P., Ji, S. R., Hou, C., Tang, H. Y., Wang, Q., and Shen, Y. X. (2016). Effects of chemical additives on the fermentation quality and $\mathrm{N}$ distribution of alfalfa silage in south of China. Anim. Sci. J. 87, 1472-1479. doi: 10.1111/asj. 12600

\section{FUNDING}

This work was supported by the financial support received from the Chinese Academy of Sciences, Strategic Priority Research Program (Nos. XDA26040304, XDA26040306, and XDA26040203) and Hunan Provincial Science and Technology Department (No. 2019RS3021).

Li, R. R., Jiang, D., Zheng, M. L., Tian, P. J., Zheng, M. H., and Xu, C. C. (2020). Microbial community dynamics during alfalfa silage with or without clostridial fermentation. Sci. Rep-Uk. 10, 17782. doi: 10.1038/S41598-020-74958-1

McGarvey, J. A., Franco, R. B., Palumbo, J. D., Hnasko, R., Stanker, L., and Mitloehner, F. M. (2013). Bacterial population dynamics during the ensiling of Medicago sativa (alfalfa) and subsequent exposure to air. J. Appl. Microbiol. 114, 1661-1670. doi: 10.1111/jam.12179

Muck, R. E. (2010). Silage microbiology and its control through additives. R. Bras. Zootec. 39, 183-191. doi: 10.1590/S1516-35982010001300021

Muck, R. E., Nadeau, E. M. G., McAllister, T. A., Contreras-Govea, F. E., Santos, M. C., and Kung, L. (2018). Silage review: Recent advances and future uses of silage additives. J. Dairy Sci. 101, 3980-4000. doi: 10.3168/jds.2017-1 3839

Namihira, T., Shinzato, N., Akamine, H., Maekawa, H., and Matsui, T. (2010). Influence of nitrogen fertilization on tropical-grass silage assessed by ensiling process monitoring using chemical and microbial community analyses. J. Appl. Microbiol. 108, 1954-1965. doi: 10.1111/j.1365-2672.2009.04591.x

Ogunade, I. M., Jiang, Y., Cervantes, A. A. P., Kim, D. H., Oliveira, A. S., Vyas, D., et al. (2018). Bacterial diversity and composition of alfalfa silage as analyzed by Illumina MiSeq sequencing: effects of Escherichia coli O157:H7 and silage additives. J. Dairy Sci. 101, 2048-2059. doi: 10.3168/jds.2017-12876

Queiroz, O. C. M., Ogunade, I. M., Weinberg, Z., and Adesogan, A. T. (2018). Silage review: foodborne pathogens in silage and their mitigation by silage additives. J. Dairy Sci. 101, 4132-4142. doi: 10.3168/jds.2017-13901

Rohweder, D. A., Barnes, R. F., and Jorgensen, N. (1978). Proposed hay grading standards based on laboratory analyses for evaluating quality. J. Anim. Sci. 47, 747-759. doi: 10.2527/jas1978.473747x

Sengul, M., and Sengul, S. (2008). Chemical composition and nutritional properties of Landraces alfalfa (Medicago sativa L.) cultivars. Asian J. Chem. 20, 32183226.

Sun, Z. Q., Jia, T. T., Gao, R., Xu, S. Y., Wu, Z., Wang, B., et al. (2020). Effects of chopping length and additive on the fermentation quality and aerobic stability in silage of Leymus chinensis. Processes 8:1283. doi: 10.3390/Pr8101283

Vansoest, P. J., Robertson, J. B., and Lewis, B. A. (1991). Methods for dietary fiber, neutral detergent fiber, and nonstarch polysaccharides in relation to animal nutrition. J. Dairy Sci. 74, 3583-3597. doi: 10.3168/jds.S0022-0302(91)78 $551-2$

Wang, B., Gao, R., Wu, Z., and Yu, Z. (2020). Functional analysis of sugars in modulating bacterial communities and metabolomics profiles of Medicago sativa silage. Front. Microbiol. 11:641. doi: 10.3389/Fmicb.2020.00641

Wang, C., He, L. W., Xing, Y. Q., Zhou, W., Yang, F. Y., Chen, X. Y., et al. (2019a). Fermentation quality and microbial community of alfalfa and stylo silage mixed with Moringa oleifera leaves. Bioresource Technol. 284, 240-247. doi: 10.1016/j.biortech.2019.03.129

Wang, Y., He, L. W., Xing, Y. Q., Zhou, W., Pian, R. Q., Yang, F. Y., et al. (2019c). Bacterial diversity and fermentation quality of Moringa oleifera leaves silage prepared with lactic acid bacteria inoculants and stored at different temperatures. Bioresource Technol. 284, 349-358. doi: 10.1016/j.biortech.2019. 03.139

Wang, Y., Chen, X. Y., Wang, C., He, L. W., Zhou, W., Yang, F. Y., et al. (2019b). The bacterial community and fermentation quality of mulberry (Morus alba) leaf silage with or without Lactobacillus casei and sucrose. Bioresource Technol. 293:122059. doi: 10.1016/j.biortech.2019.122059

Weatherburn, M. W. (1967). Phenol-hypochlorite reaction for determination of ammonia. Anal. Chem. 39, 971-974. doi: 10.1021/Ac60252a045

Xu, H. Y., Li, Z. Y., Tong, Z. Y., He, F., and Li, X. L. (2020). Metabolomic analyses reveal substances that contribute to the increased freezing tolerance of alfalfa (Medicago sativa L.) after continuous water deficit. Bmc Plant Biol. 20:15. doi: 10.1186/s12870-019-2233-9 
Zhang, Q., Yang, H., and Yu, Z. (2017). Effects of sucrose, formic acid and lactic acid bacteria inoculant on quality, in vitro rumen digestibility and fermentability of drooping wild ryegrass (Elymus nutans Griseb.) silage. J. Anim. Feed Sci. 26, 26-32. doi: 10.22358/jafs/68802/2017

Zhang, Q., Yu, Z., Wang, X. G., and Tian, J. P. (2018). Effects of inoculants and environmental temperature on fermentation quality and bacterial diversity of alfalfa silage. Anim. Sci. J. 89, 1085-1092. doi: 10.1111/asj.1 2961

Conflict of Interest: The authors declare that the research was conducted in the absence of any commercial or financial relationships that could be construed as a potential conflict of interest.
Publisher's Note: All claims expressed in this article are solely those of the authors and do not necessarily represent those of their affiliated organizations, or those of the publisher, the editors and the reviewers. Any product that may be evaluated in this article, or claim that may be made by its manufacturer, is not guaranteed or endorsed by the publisher.

Copyright (c) 2021 Kang, Tang, Zhong, Tan and Wu. This is an open-access article distributed under the terms of the Creative Commons Attribution License (CC BY). The use, distribution or reproduction in other forums is permitted, provided the original author(s) and the copyright owner(s) are credited and that the original publication in this journal is cited, in accordance with accepted academic practice. No use, distribution or reproduction is permitted which does not comply with these terms. 